\title{
perVERSIONES: a voz performática de Fátima Miranda
}

\section{perVERSIONES: the performative voice of Fátima}

Miranda

Wânia Mara Agostini Storolli 


\section{Resumo}

Baseado na performance perVERSIONES de Fátima Miranda e em entrevista concedida pela artista a esta autora, este artigo relata sobre a qualidade performativa da voz, sobre as relações entre voz, dramaturgia e performance, revelando a potencialidade criativa da voz como geradora de uma linguagem artística singular. Como um amálgama sonoro, a voz de Fátima Miranda é capaz de fundir tradições diversas, dissolver as fronteiras entre as artes e provocar a transformação de nossa percepção.

Palavras-chave: Fátima Miranda; voz performática; vocal performance art

\section{Abstract}

Based on the performance perVERSIONES by Fátima Miranda and on an interview granted to this author by the artist, this article discusses the performative quality of the voice, as well as the relations between voice, dramaturgy and performance, in order to reveal the creative potential of the voice for the development of a unique artistic language. As a sound amalgam, the voice of Fátima Miranda is able to interweave diverse traditions, to dissolve the boundaries between the arts and to transform our perception.

Keywords: Fátima Miranda; performative voice; vocal performance art

ISSN: 1414.5731
${ }^{1}$ Este estudo faz parte de pesquisa de pós-doutorado, realizada com apoio da FAPESP.
2 Pós-doutoranda do Departamento de Música da ECA/USP. São Paulo, SP, Brasil waniast@gmail.com 
Através da exploração de seus registros, de diferentes formas de emissão e dos inúmeros sons que é capaz de produzir, a voz tem desempenhado papel fundamental como condutora de processos de criação artística. Os processos de experimentação revelam a enorme gama de sons vocais, trazendo à tona aspectos por vezes adormecidos pelas limitações das línguas faladas no cotidiano. Como material sonoro, a voz incorpora influências do meio, trazendo a possibilidade de fusão de culturas, suas línguas e sons. Nas diversas manifestações em que está presente, no teatro, na música, na arte sonora, na poesia experimental, surgem novos parâmetros vocais, para os quais são determinantes os movimentos das vanguardas artísticas do século XX. Em especial, a influência das vanguardas futuristas e dadaístas do início do século, responsáveis por mudanças significativas na forma de se fazer arte, se faz perceptível, norteando parte da produção artística posterior, estimulando os processos de investigação e provocando uma crescente dissolução das fronteiras artísticas, através do uso de uma mixagem de linguagens em suas manifestações. A performance é uma das formas eleitas pelas vanguardas. Nelas o corpo ganha destaque, uma tendência que se intensifica nas últimas décadas do século, com o surgimento dos Happenings e da Performance Art. Compreendida como corpo, a voz também é investigada e o aparelho fonador oferece-se como material sonoro, gerando novas possibilidades de criação. As mudanças nos critérios estéticos cooperam para o surgimento de uma voz que se deixa povoar por gritos, sussurros, gemidos, sons guturais, assobios, estalidos de língua e muitas outras possibilidades. Pouco a pouco estabelece-se uma tradição de experimentação vocal, que transita pelas diversas linguagens, gera desdobramentos junto aos processos de criação e influencia o surgimento de novas estéticas.

\section{Vocal Performance Art}

A partir das décadas de 60 e 70 observa-se a expansão de uma forma artística, que se organiza principalmente a partir da exploração dos recursos vocais, fundamentando-se na pesquisa das múltiplas possibilidades da voz, integrando sons de diversas línguas e diferentes formas de emissão vocal. Essa forma é considerada um gênero específico pela pesquisadora Weber-Lucks (2005), que propõe o termo Vocal Performance Art para designá-lo. Esse gênero teria se estabelecido predominantemente através da produção artística feminina, na esteira das novas formas como os Happenings e dos movimentos vanguardistas, tais como o Fluxus. Tanto os Happenings, forma artística consolidada primeiramente por Alan Kaprow em 1958, como o Fluxus, movimento criado em 1961 por George Maciunas, realizavam eventos que tinham em comum a interdisciplinaridade. Na década de 70, a Performance Art estabelece-se como um gênero autônomo, caracterizando-se pelo experimentalismo, pela mixagem de linguagens artísticas, pelo uso de espaços não convencionais para a realização das performances, pelo uso de recursos tecnológicos e processos de improvisação, colagem e justaposição, entre outros. O estabelecimento desse gênero é determinante para o surgimento de uma nova estética e coopera para a dissolução das zonas limítrofes entre as categorias tradicionais. Nesse contexto de experimentação e surgimento de novos gêneros, desenvolve-se também a Vocal Performance Art, relacionando-se com as novas estéticas e novas formas de performance. 
Entre os artistas que cooperaram para o estabelecimento da Vocal Performance Art pode-se mencionar, entre outros, Cathy Berberien, Demetrio Stratos, Joan La Barbara, Meredith Monk, Diamanda Galás, David Moss, Laurie Anderson e Fátima Miranda. O centro do trabalho desses artistas é a pesquisa vocal, e o processo de criação no âmbito desse gênero liga-se fortemente às possibilidades individuais de cada performer. Nesse sentido, as obras resultantes apresentam um caráter singular e de difícil realização por outros que não os próprios criadores, já que, "as técnicas vocais utilizadas são via de regra desenvolvidas segundo as possibilidades individuais, vocais e de articulação, e por isto dificilmente a outros transmissíveis" (Weber-Lucks, 2005, p. 7 - tradução nossa. ${ }^{3}$ Explorando a voz e sua característica privilegiada de poder transitar facilmente entre as diversas linguagens, a Vocal Performance Art parte da criação vocal, que mixada a outras linguagens incorpora na performance algumas características da Performance Art, introduzindo por vezes elementos do teatro, da música, da dança, do cinema e do vídeo. De fato, no âmbito deste gênero não apenas são desenvolvidas novas possibilidades vocais, mas também novas formas de performance.

O desenvolvimento de processos criativos a partir da pesquisa vocal e das relações entre voz e performance é determinante na geração de linguagens artísticas singulares. Como exemplo, este artigo relata sobre o processo criativo de Fátima Miranda, enfatizando como a investigação da própria voz, a assimilação e mixagem de tradições vocais diversas, bem como as relações que se estabelecem entre voz, dramaturgia e performance são fundamentais para a configuração de sua linguagem artística. $O$ estudo fundamenta-se em registros audiovisuais do espetáculo perVERSIONES e na própria performance ao vivo, encenada por Fátima Miranda em Madrid em maio de 2011, durante o XXVIII Festival de Otõno en Primavera, assim como na entrevista concedida pela artista a esta autora em junho de 2011, em Madrid.

\section{Vozes da voz: a arte de Fátima Miranda}

Desdobrando sua voz em muitas, Fátima Miranda, natural de Salamanca, na Espanha, é um exemplo de criadora, cantora e performer que, a partir de processos experimentais e da pesquisa vocal, desenvolve uma linguagem artística singular. Atuando no território das fronteiras entre as artes, a artista integra a criação vocal na realização de suas performances multimídia. Em seu processo criativo, a voz é o elemento propulsor que, explorada com maestria e virtuosismo, norteia e estimula a configuração de uma performance com características únicas.

Considerando-se antes de mais nada uma criadora, Fátima Miranda inicia sua trajetória através da participação no grupo Taller de Música Mundana em 1979, a partir do convite de Llorenç Barber, músico, compositor e musicólogo, segundo Weber-Lucks (2003). Em entrevista, Fátima Miranda comenta como sua formação

\footnotetext{
3 "Die verwendeten Stimmtechniken sind in der Regel auf dessen individuelle, artikulatorische und stimmliche Möglichkeiten zugeschnitten und daher nur schwer übertragbar."
} 
artística ocorre no ambiente estimulante e inovador da produção contemporânea através da própria atuação: "Comecei ao revés [...] as pessoas começam estudando, eu comecei diretamente no palco [...]" (Miranda, 2011). Com forte enfoque experimental e inspirado em John Cage, esse grupo, composto na maioria por participantes sem formação musical acadêmica, é sua escola de improvisação. Nele, Fátima Miranda tem a oportunidade de desenvolver suas primeiras pesquisas, que consistem em investigar diversos materiais e suas sonoridades peculiares, tais como os sons da água, das pedras, do papel. Com esse grupo apresenta uma performance desenvolvida a partir dos sons de papel e posteriormente até mesmo uma ópera composta apenas com esse material sonoro. Na Opera para papel, o grupo faz uso de sons produzidos por diferentes tipos de papel (celofane, papel de seda, jornais, papelão, papel de alumínio etc.), juntamente com um trabalho de cena, luzes e até mesmo odores, provenientes da queima de papel realizada durante a própria performance. O resultado sonoro resulta principalmente "da interação entre os participantes, da reação sensível ao estímulo do outro, compondo um processo de trabalho coletivo e improvisacional" (Nauck, 1996, p. 26 - tradução nossa), ${ }^{4}$ onde todos sabem o que vão fazer, mas não como vão fazer, o que é determinado pelo momento, pelo espaço e pela atmosfera do local.

O trabalho junto ao grupo Taller de Música Mundana desperta Fátima Miranda para um percurso de investigações sonoras. É um período de pesquisas e descobertas, funcionando como uma escola que privilegia a investigação e a criatividade, que não impõe caminhos, mas que deixa seus participantes encontrá-los. A improvisação livre é a base deste trabalho. O material sonoro, o jogo entre os participantes e uma audição sensível orientam a realização das performances, assim como a relação com o espaço onde se realizam. A voz é no início apenas uma entre outras fontes sonoras pesquisadas, como a própria Fátima Miranda relata:

Comecei a ensaiar com objetos encontrados. Com uma atitude muito dadaísta. Eu ensaiava com metais, com tubos de plásticos, com conchas, com cornetas, com papel, papelão, plástico, panelas, pedras, tudo o que encontrava [...] eu improvisava com pedaços de bambu, pedaços de madeira [...] E foi nestes ensaios, que motivada pelos ritmos e pelo trabalho que se fazia, que a voz saiu como uma reação, mas sem buscá-la [...] eu não buscava. Na realidade foi o contrário, eu trabalhava de maneira orgânica, trabalhava com sons e a voz saia como consequência disto [...] Claro, como eu não sabia cantar, a voz saia de uma maneira singular [...] Há uma frase muito bonita de Santo Agostinho: eu não a teria buscado, se não a tivesse encontrado. Eu não busquei a voz, a encontrei (Miranda, 2011).

A partir de seu envolvimento com esse grupo e também estimulada pela relevância que sua voz passa a ter, Fátima Miranda começa a aprimorar o conhecimento de seu aparato vocal, dedicando-se a uma pesquisa pessoal e ao estudo de diversas tradições vocais. Em 1986, Fátima Miranda cria com Llorenç Barber o grupo de poesia fonética Flatus Vocis Trío. Descobre assim a musicalidade da fala, a potencialidade sonora das palavras, enriquecendo sua pesquisa vocal. Des-

\footnotetext{
4 "[...] aus dem Miteinander-Agieren und dem sensiblen Aufeinander-Reagieren, einen kollektiven, stark improvisatorisch bestimmten Erarbeitungsprozeß vorausgesetzt."
} 
te trabalho provém, segundo Barber, "as inúmeras personagens que sua voz desenha com toques de ironia e suas falas diferentes, de verdureiros a anjos" (Barber, 2000, p. 9 - tradução nossa). ${ }^{5}$ Juntamente com a pesquisa da voz e incorporação de técnicas vocais diversas, que não se substituem, mas se adicionam, Fátima Miranda mantém um catálogo dos próprios recursos vocais, resultante das primeiras experiências nos grupos Taller de Música Mundana e Flatus Vocis Trío. Nomeia os sons de sua voz, tais como "sons de pranto" e "voz de cristal", um som agudíssimo que não parece humano. Para ela, as técnicas vocais são todas compatíveis, mas o treinamento é fundamental, não apenas treinar a voz, mas também o ouvido e o corpo inteiro. A improvisação não é compreendida como algo que se realiza sem preparo. Ao contrário, a liberdade gerada pela improvisação reside em poder eleger o que se quer fazer. Improvisar não significa para Fátima Miranda fazer "qualquer coisa que surja no momento", mas algo que resulte deste constante e árduo preparo de seu corpo (Miranda, 2011).

Em sua obra há principalmente uma desvinculação entre palavra e significado semântico, a palavra é desconstruída e explorada em toda sua possibilidade sonora. A influência do dadaísmo e da poesia fonética faz-se sentir claramente em suas criações. As técnicas decorrem de sua pesquisa com a própria voz, mas também resultam de uma procura determinada, do interesse pelas diversas tradições vocais, aparentemente tão distintas quanto irreconciliáveis, que podem no entanto conviver em suas múltiplas vozes. Existe o desejo de recuperar possibilidades sonoras primordiais da voz, desejo que conduz a uma pesquisa constante e que revela a enorme diversidade dos sons vocais. Relatando sobre o trabalho no grupo Flatus Vocis Trío, Fátima Miranda observa não existir "a pretensão de descobrir algo novo" e que "em certa medida se volta en-cantado às fontes" (Miranda, 2011).

A voz de Fátima Miranda transforma-se pouco a pouco numa espécie de amálgama, incorporando influências do ocidente e do oriente, entrelaçando tradições distintas como o Bel Canto, o canto difônico mongol e o canto Dhrupad do norte da Índia. É a partir desta mistura de influências e tradições vocais, combinada com uma pesquisa pessoal e uma potencialidade dramática natural, que surge a primeira obra individual de Fátima Miranda - Las Voces de la Voz (1991), título que expressa o seu trabalho vocal, que revela as muitas vozes que uma voz carrega. Nesta e nas próximas obras, a voz de Fátima Miranda não é apenas canto ou fala, mas transita por diversas tradições e linguagens, pela música, pelo teatro, pela poesia, pela arte sonora, fundindo não somente as técnicas aprendidas, mas também as desenvolvidas por ela. Em 1994 surge Concierto en Canto, revelando claramente a influência do canto Dhrupad, aprendido durante sua estadia na Índia. Em 2000 Fátima Miranda apresenta ArteSonado, em 2005 estreia Cantos Robados e em 2011 perVERSIONES.

\footnotetext{
5 "[...] los mil personajes que su voz dibuja con toques de ironia, y sus hablares disímiles - entre verduleros y angelicales."
} 


\section{PERVERSIONES}

O espetáculo perVERSIONES, criado e encenado por Fátima Miranda, tem sua estréia mundial em 20 de janeiro de 2011 no Teatro Municipal da Guarda, em Portugal, entrelaçando temas introspectivos e extrovertidos, cotidianos e sagrados. perVERSIONES é estruturada em sete partes: cada uma congrega três ou quatro canções que giram em torno de uma atmosfera específica sugerida. O título traz tanto a noção de que as canções escolhidas serão objeto de uma versão pessoal de Fátima Miranda, como também de que a artista irá perverter e transformar o sentido comum destas canções. Mas esta perversão irá mais além, pois através de uma performance que integra elementos sonoros e visuais, com imagens criadas por Chema Madoz, Fátima Miranda também consegue despertar no público outras formas de ouvir, ver e perceber, pervertendo assim a percepção usual dos que estão presentes. Como a própria Fátima Miranda observa no programa do espetáculo, o que a interessa é dar "outro sabor, outro perfume, outro destino" às canções escolhidas, de forma que o ouvinte-espectador possa vivenciar "uma experiência que dê unidade e sentido" ao encontro. Trata-se aqui de uma performance, que se diferencia fundamentalmente das obras anteriores de Fátima Miranda. Diferentemente da maior parte de suas performances, que são organizadas a partir de criações originais, perVERSIONES traz obras de outros autores, hits consagrados que fazem parte da memória coletiva.

perVERSIONES teria sido talvez o primeiro projeto de Fátima Miranda, anterior a todos os outros, como a própria artista comenta (Miranda, 2011). Porém, realizando o projeto em 2011, em um momento em que já desfruta de maturidade artística, pode emprestar a canções consagradas uma interpretação absolutamente pessoal, reinventando cada uma delas através do uso de diversos procedimentos e elementos oriundos de sua linguagem artística, desenvolvida durante sua trajetória como criadora e performer nas últimas décadas. Trata-se portanto de um espetáculo em que Fátima Miranda enfrenta o desafio de executar canções consagradas que vão de melodias medievais, lamentos e ragas a standards do jazz, bossa nova, canção pop, fado, lied e chanson, abarcando compositores eruditos e populares, tais como Franz Schubert, Erik Satie, Kurt Weill, Gabriel Fauré, Antonio Carlos Jobim, Lou Reed, Alfredo Duarte e Arthur Hamilton, entre outros. Contracenando com o pianista Miguel Ángel Alonso Mirón, Fátima Miranda recria, desconstrói e subverte as canções originais, entrelaçando nesta performance diversas linguagens, onde a dramaturgia é sugerida tanto por sua atuação como pelos materiais sonoros e visuais.

\section{Uma voz infinita: a dimensão do sagrado}

Circundada por um espaço repleto de estrelas, envolta em vestes brancas que lembram as tradicionais utilizadas na dança sagrada dos Derviches, Fátima Miranda aparece sob uma luz azul girando em torno de si mesma, tal qual um astro, anunciando que estamos prestes a adentrar na dimensão do sagrado. $O$ som 
agudo de um sino ressoa, repetida e pausadamente, convocando-nos para uma celebração, uma vivência em conjunto, que tem lugar no espaço-tempo da própria performance. O giro Derviche realizado por Fátima Miranda, oriundo das tradições sufis, associado a rituais e tradições musicais, é uma espécie de meditação em movimento. Dando voltas em torno do próprio eixo, no sentido anti-horário, o giro celebra o desejo de comunhão e conexão com o sagrado. É realizado com os braços abertos, com a palma direita para cima, braço direito para o alto e o esquerdo levemente para baixo, promovendo a conexão entre céu e terra. Mas não é apenas o giro, senão a própria voz de Fátima Miranda que, logo em seguida, ao executar Salmo Copto, anuncia a possibilidade de vivência do sagrado. Com uma qualidade que parece se distanciar da voz humana, trazendo a noção da dimensão do cosmo, surge a voz de Fátima Miranda, revelando que a voz também pode ser atemporal e conectar o cotidiano ao sagrado, expandindo as fronteiras do próprio corpo do qual emana e provocando também essa expansão naqueles que participam desta vivência.

A pequena figura de Fátima Miranda torna-se imensa através de sua voz, preenchendo todos os espaços da Sala Verde dos Teatros Del Canal em Madrid, onde esta performance integrou o programa do XXVIII Festival de Otõno en Primavera, em maio de 2011. Não se consegue determinar ao certo de onde vem essa voz, mas já no primeiro momento a audiência é tomada de emoção, espanto e também de um certo estranhamento. De fato, a voz e a atuação desta performer singular no palco são capazes de dilatar seu corpo real, fazendo-se presente em cada ponto do teatro e em cada indivíduo ali presente. Através da integração de nossos sentidos o público passa a fazer parte desta performance, que não atinge apenas a audição e visão dos presentes, mas envolve a percepção de um modo geral, lembrando que também o espaço da performance pode constituir um espaço sagrado.

Salmo Copto, canto anônimo, inaugura a primeira parte da performance, intitulada Dioses: ruegos y preguntas. Após o Salmo Copto, ainda nesta primeira parte, Fátima Miranda apresenta uma obra tradicional da Índia, Composición para Raga Bhairavi. Segue-se então uma criação da própria Fátima Miranda - Saeta, composta segundo tradição espanhola. Esta forma de canção tradicional é em geral composta para voz solo, onde aquele que a executa mostra devoção a uma imagem particular de Cristo. A performance de Fátima Miranda tem como cenário a projeção de múltiplas figuras de uma imagem de Cristo na cruz, porém um Cristo com quatro braços, revelando a fusão de sua imagem com a do deus Shiva. A cada batida que soa há uma redução do número de figuras, num processo de zoom resta ao final apenas uma grande e imensa figura, um deus que parece ser ainda mais onipotente, presente atrás da artista. Substituindo o céu estrelado, esta imagem imensa revela, juntamente com a voz de Fátima Miranda, a fusão das culturas e tradições - pano de fundo para uma execução vocal densa e trágica, na qual roga a performer frente ao público e frente a este deus misto, lembrando a todos da inexorabilidade do destino humano.

O impacto que esta primeira parte do espetáculo provoca revela como a obra de Fátima Miranda, embora originada a partir de seu trabalho com a voz, 
também se constrói em torno das relações entre voz, dramaturgia e performance, onde elementos como cenografia e iluminação desempenham um papel relevante. Em seu trabalho, o processo de investigação vocal, o emprego dos diversos recursos da voz estimulam a criação de uma dramaturgia, e por sua vez, o contexto dramatúrgico desenvolvido exige performances vocais específicas, de modo que a relação entre voz, dramaturgia e performance ocorre num crescendo, de forma espiralada, um elemento estimulando, influenciando e alimentando o outro. Este processo criativo culmina com a apresentação, mas não termina aí, pois a experiência da performance pública estimula também novas orientações e mudanças na própria performance, na pesquisa diária e na atividade de criação, de modo que o processo revela-se como infindável, reverberando seus efeitos no público. Infindáveis parecem também ser os recursos das muitas vozes de Fátima Miranda, integrando as diversas técnicas desenvolvidas por ela ou aprendidas. Como a artista relata: "Se incorporo uma técnica vocal diferente, nova, não significa que preciso eliminar a anterior" (Miranda 2011), uma noção bastante distinta da usual, colocando à disposição desta performer uma gama enorme de possibilidades de emissão vocal, desde a técnica do bel canto, poesia fonética e Sprechgesang até tradições diversas provenientes do oriente.

\section{Versões e desconstruções}

Na segunda parte do espetáculo, intitulada Lágrimas, o sabor da experimentação típico da música contemporânea é emprestado a Flow my tears de John Dowland. A recriação desta canção traz alguns procedimentos, tal como o piano preparado e o uso de objetos do cotidiano, que remetem ao compositor John Cage, a quem a canção é dedicada. Fátima Miranda executa a primeira estrofe com voz solo, porém através de um tubo de plástico direcionado para as cordas do piano. Logo em seguida, de posse de uma escova azul, a performer faz dela uso para tocar as cordas do piano, nos dando através da sonoridade obtida a ilusão do instrumento original utilizado por Dowland. Embora a emissão vocal de Fátima Miranda não se diferencie das realizadas usualmente para esta canção, a realização de sua performance, com a utilização de elementos como o tubo de plástico e a escova, com a qual a artista passa a brincar, desconstrói totalmente a interpretação tradicional, em geral povoada de caretas de sofrimento estilizadas. No momento em que Fátima Miranda utiliza a escova para coçar seus ombros e limpar suas unhas, instaura também um distanciamento em relação à obra e estimula uma outra forma de percepção, que não se baseia mais na identificação, mas sim no estranhamento. Humor e ironia, elementos que fazem parte da linguagem artística de Fátima Miranda, estão presentes em vários momentos de perVERSIO$N E S$, denotando sua atitude Dada, que abala as interpretações tidas como sérias e infringem as regras e a estética usual.

O espetáculo traz ainda canções consagradas como Cry me a River de Arthur Hamilton e Chega de Saudade de Antonio Carlos Jobim, procedendo a sua desconstrução. Com fina ironia e humor Fátima Miranda as perverte. Em Cry me a River há o exagero vocal e de sentimentos, deixando-se aflorar o aspecto melo- 
dramático e uma voz furiosa, que delineia o sentimento que esta canção suscita. O clássico da bossa-nova Chega de Saudade de Tom Jobim, que integra a sexta parte do espetáculo intitulada No more blues, também não escapa ao fino humor de Fátima Miranda. Interrompendo repetida e ritmicamente o fluxo da voz ao virar o rosto para os lados, como se estivesse a mudar a estação de rádio, Fátima Miranda interrompe a melodia cortando as palavras, de modo que ouvimos apenas fragmentos destas, passando então a fazer uso de uma glossolalia, uma língua inventada. Este clássico brasileiro termina tal qual uma brincadeira de crianças, com o jogo de bater de mãos com o pianista Mirón, acompanhado pelo verso final "não quero mais este negócio de você viver sem mim", revelando como cada detalhe é extremamente preciso.

Mas nem tudo é ironia e humor. A performance de Fátima Miranda também pode criar momentos de introspecção, como em Strange Fruit de Lewis Allan, canção que ficou imortalizada na voz de Billie Holliday e que integra a última parte do espetáculo, intitulada Adioses. Aqui não há espaço para ironia, mas apenas para a realização do som de vento no início e término da canção, um sopro que anuncia a queda desta estranha fruta. Encerrando o espetáculo, Après un revê de Gabriel Fauré, traz Fátima Miranda envolta por uma folha de papel transparente, com a qual contracena produzindo imagens belíssimas e oníricas. Como observado no programa da performance, este repertório eclético é capaz de criar "um mapa sem fronteiras que por sua vez dirige-se a e emerge da memória coletiva". Fátima Miranda interage com o cenário, as luzes, o figurino e a história destas canções de "toda a vida", integrando as diversas linguagens de modo a ofuscar suas fronteiras. Proporciona, através de suas perVERSIONES, uma experiência única e a transformação da percepção de todos os presentes. Como o título sugere, através desta performance Fátima Miranda revela um sabor distinto através da execução das canções escolhidas, propiciando ao ouvinte-espectador uma outra escuta, um outro sentir.

\section{Dissolução das fronteiras}

Assim como uma parcela da produção artística contemporânea, o trabalho de Fátima Miranda orienta-se a partir de uma mixagem de linguagens, em que a performance é fundamental, abrangendo não somente a voz, como também o movimento, os cenários, luzes e figurinos, onde cada elemento é detalhadamente pensado e planejado. A voz é o território de Fátima Miranda, uma voz que atravessa as diversas linguagens, trazendo personagens diversas e fundindo diferentes tradições vocais através de um registro privilegiado de quatro oitavas. Em seu trabalho, as fronteiras entre as linguagens se interpõem, "entre o que é música, canto, performance, poesia em geral, poesia fonética, composição, interpretação. São fronteiras muito sutis, praticamente não existem [...]" (Miranda, 2011). Tudo, no entanto, origina-se na voz. A dramaturgia surge como um componente fundamental, entrelaçando as criações e organizando as performances. Há um diálogo contínuo entre as vozes de Fátima Miranda e as performances que estas podem gerar, os contextos e personagens que podem criar. Estes por 
sua vez estimulam a geração de outras vozes, tornando as fronteiras entre criação e performance indefinidas. Se as vozes sugerem um contexto, a dramaturgia idealizada conduz também à descoberta de outras vozes, uma intrincada trama onde os fios se confundem.

Como outras performances de Fátima Miranda, perVERSIONES caracterizase por ter a voz como propulsora de um processo criativo singular. Neste espetáculo, Fátima Miranda recria e reinterpreta canções que fazem parte da memória coletiva a partir de suas impressões e ideias pessoais, estimulada pela dramaturgia sugerida pelas próprias canções, observando-se uma forte relação entre voz, dramaturgia e performance. Sua performance vocal é única, porém o que torna seu trabalho ainda mais singular é a relação entre voz, cena, dramaturgia, cenário, iluminação e sua própria movimentação e atuação no palco. Nesse sentido, não é possível falar do trabalho de Fátima Miranda sem considerar a presença e integração das diversas linguagens artísticas. A voz de Fátima Miranda é capaz de nos tranportar tanto para tempos remotos, possibilitando a vivência de tradições musicais seculares, assim como iluminar o momento atual, estimulando um aguçamento de nossa percepção. Sua voz transita pelas diversas linguagens, decompõe-se em muitas outras, atravessando o espaço ora como uma agudíssima voz irreal, a "voz de cristal", ora com a potência dramática característica de sua identidade espanhola. Realizando os sons mais inusitados, reunindo diversas tradições vocais, sua performance toca no sagrado, mas também no cotidiano, no sério e no divertido, no trágico e no melodramático, entrelaçando atmosferas diversas, que abarcam do íntimo e introvertido ao irônico e extrovertido. A voz performática de Fátima Miranda é capaz de fundir tradições e linguagens diversas, dissolvendo as fronteiras entre as artes, recriando e pervertendo canções, de modo a transformar nossa percepção, nos possibilitando uma vivência única e especial.

\section{Referências}

BARBER, Llorenç. Fátima Miranda: una voz muy particular. In ArteSonado (Livro-Cd de Fátima Miranda). Madrid, El Europeo Musica-52 PM, Colección LCD 19, p. 8-21, 2000.

MIRANDA, Fátima. Entrevista concedida a Wânia Storolli. Madrid, em 03 jun. 2011.

PerVERSIONES. Performance. XXVIII Festival de Otõno en Primavera. Madrid: Teatros del Canal, 31 maio 2011.

Sobre Flatus Vocis Trío. Disponível em: <http://www.fatima-miranda.com>. Acesso em: 14 maio 2011.

NAUCK, Gisela. Spanischer Minimalismus aus dem Geist von Fluxus. Die paper opera der gruppe Taller de Música Mundana. Positionen. Berlin, n. 28, p. 26-28, 1996.

WEBER-LUCKS, Theda. Körperstimmen: Vokale Performancekunst als neue musikalische Gattung. Berlin: 2005. Tese (Doutorado) - Technische Universität. 
WEBER-LUCKS, Theda. Schier grenzenlose Stimmkunst. Die Spanierin Fátima Miranda. MusikTexte, Aug. 2003, p. 5-10.

\section{Videografia}

MIRANDA, Fátima. PerVersiones: fragmentos. Disponível em: <http://vimeo. com/28426846>. Acesso em: 07 jan. 2012.

Recebido em 06/05/2014 Aprovado em 26/06/2014 